\title{
Natriuretic peptides in the detection of preclinical diastolic or systolic dysfunction
}

\author{
Claus Luers • Rolf Wachter $\cdot$ Sibylle Kleta $\cdot$ Marc Uhlir • Janka Koschack • \\ Martin Scherer • Lutz Binder · Christoph Herrmann-Lingen • Antonia Zapf • \\ Bettina Kulle $\cdot$ Michael M. Kochen $\cdot$ Burkert Pieske
}

Received: 29 May 2009/ Accepted: 22 December 2009/Published online: 6 January 2010

(C) The Author(s) 2010. This article is published with open access at Springerlink.com

\begin{abstract}
Aims The diagnostic value of natriuretic peptides in asymptomatic patients at risk for diastolic or systolic HF is controversial. We tested (1) the prevalence of preclinical LV dysfunction in an at-risk cohort; (2) the diagnostic accuracy of natriuretic peptides alone or in combination
\end{abstract}

C. Luers and R. Wachter contributed equally to this work.

C. Luers $(\square) \cdot$ R. Wachter $\cdot$ S. Kleta $\cdot$ M. Uhlir $\cdot$ B. Pieske

Department of Cardiology and Pneumology,

University of Goettingen, Robert-Koch-Str. 40,

37075 Goettingen, Germany

e-mail: cluers@gwdg.de

J. Koschack · M. Scherer · M. M. Kochen

Department of Family Medicine, University of Goettingen,

Goettingen, Germany

\section{Scherer}

Institute of Social Medicine, University of Luebeck,

Luebeck, Germany

L. Binder

Department of Clinical Chemistry, University of Goettingen,

Goettingen, Germany

C. Herrmann-Lingen

Department of Psychosomatic Medicine and Psychotherapy,

University of Goettingen, Goettingen, Germany

\author{
A. Zapf \\ Department of Medical Statistics, University of Goettingen, \\ Goettingen, Germany \\ B. Kulle \\ Section of Medical Statistics, Department of Mathematics, \\ University of Oslo, Oslo, Norway \\ B. Pieske \\ Department of Cardiology, University of Graz, Graz, Austria
}

with clinical parameters for predicting asymptomatic left ventricular systolic or diastolic dysfunction.

Methods 542 primary care patients (mean age $63 \pm$ 11 years, $42 \%$ female) without prediagnosed HF, but with risk factors for left ventricular dysfunction, underwent thorough cardiological workup, including echocardiography and analysis of natriuretic peptides.

Results 23 patients (4\%) showed reduced systolic function $(\mathrm{EF}<50 \%)$, and 15 patients $(3 \%)$ had severe diastolic dysfunction. All natriuretic peptides significantly increased with decreasing ejection fraction and with increasing degree of diastolic dysfunction. For natriuretic peptides, receiver operating characteristics analysis yielded good results for the detection of systolic dysfunction or severe diastolic dysfunction. Combining clinical parameters with natriuretic peptide data improved the diagnostic accuracy and largely reduced the number of needed screening echoes to identify patients with LV systolic or diastolic dysfunction.

Conclusions The prevalence of preclinical diastolic dysfunction is high in primary care patients at risk, but the relative prevalence of severe diastolic dysfunction and systolic dysfunction is only $7 \%$. High-risk individuals may be screened most efficiently by using a score system incorporating clinical data and NT-proBNP.

Keywords Natriuretic peptides .

Left ventricular function - Diastolic dysfunction .

Heart failure

\section{Introduction}

Systolic and diastolic heart failure (HF) are common and costly diseases and represent the most common discharge diagnosis for hospitalised patients in the United States and 
Europe [20]. HF is one of the leading causes of morbidity and mortality and a progressive disease often resulting from clinically unapparent forms of ventricular dysfunction. Recent guidelines have suggested novel definitions for staging HF that now include patients at risk or with preclinical left ventricular dysfunction (stages A and B of the AHA/ACC HF classification), which are believed to be precursors of symptomatic HF [3, 29].

Systolic dysfunction has been found to be associated with an increased risk to develop symptomatic systolic HF. About $50 \%$ of individuals with left ventricular systolic dysfunction remain undiagnosed and untreated, although early therapy may improve outcome [1].

Diastolic dysfunction is believed to be a precursor of diastolic HF, but the impact of early therapy on the risk to develop symptomatic HF is less well defined. Treatment of hypertension may improve diastolic function, and this gives advice to aggressively treat diastolic dysfunction [33].

New strategies, needed to identify and treat patients with or at risk for the development of congestive HF in a more cost-effective way, may include early treatment of preclinical stages of $\mathrm{HF}$ (stage B) to prevent or delay the progression to symptomatic HF stages $\mathrm{C}$ and $\mathrm{D}$.

Considering the large number of patients at risk for or with asymptomatic left ventricular dysfunction, interest is growing in the use of natriuretic peptides as diagnostic markers of altered left ventricular structure and function [5].

As an increase in left atrial pressure is a hallmark in moderate and severe diastolic dysfunction and the natriuretic peptide NT-proANP is predominantly secreted by the left atrium, the ratio of NT-proANP to NT-proBNP may be useful in identifying patients with severe diastolic dysfunction $[8,10,15,21,23]$.

The aim of the present study was to test the diagnostic value of natriuretic peptides in identifying patients with preclinical, asymptomatic systolic or diastolic dysfunction. Moreover, we analysed the value of the NT-proANP/NTproBNP ratio. In addition, the efficacy of different screening models based on plasma levels of natriuretic peptides, clinical information or both for the detection of preclinical ventricular dysfunction was analysed.

\section{Methods}

\section{Study population}

Between January 2003 and June 2004, 2,273 primary care patients from 58 practices in the city of Goettingen and surrounding communities were invited by their general practitioners to participate in the study. Inclusion criteria were the presence of at least one cardiovascular risk factor documented by the general practitioner (hypertension, diabetes, family history of coronary artery disease) or coronary artery disease. Patients were invited to participate by a leaflet informing about the study and a total of 542 came for the study [19]. Patients were included if they had been diagnosed to be hypertensive by their treating physician or if they were on antihypertensive therapy. Patients were classified as diabetic if this diagnosis was made by their treating physician or if they were on antihyperglycemic therapy. Coronary artery disease (CAD) was defined as angiographic evidence of CAD, a history of revascularization or a history of myocardial infarction [34]. All participants were clinically evaluated by trained cardiologists. The study complies with the Declaration of Helsinki and was approved by the local Ethics committee. All patients gave written informed consent.

\section{Echocardiography}

Echocardiography was performed by trained cardiologists using a Philips Sonos Agilent 5500 system (3.5 MHz transducer) according to standard techniques as defined by the American Society of Echocardiography [4]. An ejection fraction $(\mathrm{EF})<50 \%$, determined by Simpson's monoplane method, was defined as systolic dysfunction. None of the patients had significant primary valvular disease. Patients with normal systolic function $(\mathrm{EF} \geq 50 \%)$ were stratified according to diastolic function [27]. Transmitral left ventricular filling velocities at the tips of the mitral valve leaflets as well as E wave deceleration time (EDCT) were obtained. Isovolumetric relaxation time (IVRT) was obtained in the apical five-chamber view. Pulmonary venous flow signals were recorded in the right upper pulmonary vein and the ratio of systolic to diastolic velocity (S/D) was analysed. Velocity flow propagation $(\mathrm{Vp})$ was measured by colour Doppler $\mathrm{M}$-mode in the middle of the mitral valve.

Doppler tissue imaging was used to derive early (Ea) and late (Aa) diastolic velocities at the septal margin of the mitral annulus.

Diastolic dysfunction was classified as follows: normal diastolic function $(1<\mathrm{E} / \mathrm{A}<2,150 \mathrm{~ms}<\mathrm{EDCT}<$ $280 \mathrm{~ms}$, IVRT $<105 \mathrm{~ms}$, S/D $>1$, Ea $>8 \mathrm{~cm} / \mathrm{s}, \quad \mathrm{Vp}>$ $45 \mathrm{~cm} / \mathrm{s}$ ), mild diastolic dysfunction (E/A $<1$, EDCT $>$ $280 \mathrm{~ms}$, IVRT $>105 \mathrm{~ms}$, S/D $>1$, Ea $<8 \mathrm{~cm} / \mathrm{s}, \quad \mathrm{Vp}<$ $45 \mathrm{~cm} / \mathrm{s})$, moderate diastolic dysfunction $(1<\mathrm{E} / \mathrm{A}<2$, $150 \mathrm{~ms}<$ EDCT $<200 \mathrm{~ms}, \quad 60 \mathrm{~ms}<$ IVRT $<105 \mathrm{~ms}$, $\mathrm{S} / \mathrm{D}<1$, Ea $<8 \mathrm{~cm} / \mathrm{s}, \mathrm{Vp}<45 \mathrm{~cm} / \mathrm{s}$ ). For severe diastolic dysfunction, a restrictive filling pattern $(\mathrm{E} / \mathrm{A}>2)$ or echocardiographic signs of diastolic dysfunction in combination with two signs of elevated filling pressures were required: $\mathrm{E} / \mathrm{Ea}>15$ and left atrial diameter $>45 \mathrm{~mm}$ (for summary see Table 1) [24, 25, 32]. One of the authors (SK), blinded to all other clinical data, categorised all patients into the stage of diastolic function. Any diastolic 
dysfunction summarises all groups from mild to severe diastolic dysfunction.

Analysis of natriuretic peptides: NT-proANP, BNP, NT-proBNP

Blood was drawn under standardised conditions after a 30min supine rest on the same day as with the echocardiogram. NT-proANP was measured using a sandwich enzyme immunoassay (Immundiagnostik, Bensheim, Germany) and a Milenia microtiter plate reader. NT-proBNP and BNP were determined by means of a sandwich chemiluminescence immunoassay on an Elecsys $2010^{\circledR}$ analyzer (Roche Diagnostics, Mannheim, Germany) and a Centaur (Bayer Vital, Leverkusen, Germany), respectively. The intra-assay coefficient of variation for NT-proBNP was $1.8 \%$ for $221 \mathrm{pg} / \mathrm{mL}$ and $3.1 \%$ for $4,250 \mathrm{pg} / \mathrm{mL}$; the interassay coefficient of variation was $5.5 \%$ for $187 \mathrm{pg} / \mathrm{mL}$, $7.0 \%$ for $3,120 \mathrm{pg} / \mathrm{mL}$, and $7.3 \%$ for $12,376 \mathrm{pg} / \mathrm{mL}$. All measurements were performed in duplicate in a blinded manner by the certified core lab according to the recommendations of the manufacturer.

\section{Statistical analysis}

Data were analysed using SAS 9.1 software (SAS Institute Inc., Cary, NC, USA) and MedCalc10.0 (MedCalc Software, Mariakerke, Belgium).

Clinical parameters are expressed as mean \pm standard deviations. Natriuretic peptide plasma levels were logtransformed to get a normal distribution and were reported as median values [ 25 percentile- 75 percentile]. Differences of normally distributed variables were compared using analysis of variance (ANOVA), whereby the $p$-values reported were adjusted for multiplicity by using Bonferroni's method.

For differences of non-normally distributed variables, Mann-Whitney's $U$ test was used. Effects of covariates were assessed by multivariate stepwise logistic analysis.
All serial parameters have been tested for normal distribution. If data were found not to be normally distributed, a log-transformation was performed.

The ability of various parameters to detect left ventricular dysfunction was analysed by using the receiver-operating characteristic (ROC) curve. The optimal cut-off for each end point was chosen by the Youden criterion [35]. The developed score was validated by leave-one-out cross validation. This procedure involves using a single observation from the original sample as the validation data and the remaining observations as the training data. This is repeated such that each observation in the sample is used once as the validation data $[14,18]$. A $p$-value less than 0.05 was considered as statistic significance.

\section{Results}

Clinical and echocardiographic characteristics of the study population

For this study 542 patients were prospectively recruited (for details see Table 2). 23 patients (4\%) had a de novo diagnosis of reduced EF $(<50 \%) .352$ patients $(65 \%)$ demonstrated echocardiographic signs of isolated diastolic dysfunction (292 mild, 45 moderate, 15 severe).

Natriuretic peptides as predictors of left ventricular function

Natriuretic peptides were lowest in participants with normal systolic and diastolic functions. Plasma levels continuously increased with increasing severity of left ventricular dysfunction (Fig. 1).

Since diastolic dysfunction results in impaired left atrial emptying with increases in left atrial wall tension, we hypothesised that the ratio of NT-proBNP (released mainly from the ventricles) to NT-proANP (which is released predominantly from the atria) may be a better diagnostic

Table 1 Classification of diastolic dysfunction

\begin{tabular}{llll}
\hline Normal function & Mild diastolic dysfunction & Moderate diastolic dysfunction & Severe diastolic dysfunction \\
\hline $1<\mathrm{E} / \mathrm{A}<2$ & $\mathrm{E} / \mathrm{A}<1$ & $1<\mathrm{E} / \mathrm{A}<2$ & E/A $>2$ \\
$150 \mathrm{~ms}<\mathrm{EDCT}<280 \mathrm{~ms}$ & $\mathrm{EDCT}>280 \mathrm{~ms}$ & $150 \mathrm{~ms}<\mathrm{EDCT}<200 \mathrm{~ms}$ & - \\
$\mathrm{IVRT}<105 \mathrm{~ms}$ & $\mathrm{IVRT}>105 \mathrm{~ms}$ & $60 \mathrm{~ms}<\mathrm{IVRT}<105 \mathrm{~ms}$ & - \\
$\mathrm{S} / \mathrm{D}>1$ & $\mathrm{~S} / \mathrm{D}>1$ & $\mathrm{~S} / \mathrm{D}<1$ & - \\
$\mathrm{Ea}>8 \mathrm{~cm} / \mathrm{s}$ & $\mathrm{Ea}<8 \mathrm{~cm} / \mathrm{s}$ & $\mathrm{Ea}<8 \mathrm{~cm} / \mathrm{s}$ & - \\
$\mathrm{Vp}>45 \mathrm{~cm} / \mathrm{s}$ & $\mathrm{Vp}<45 \mathrm{~cm} / \mathrm{s}$ & - & - \\
LA diameter & - & - & $>45 \mathrm{~mm}$ \\
E/Ea & - & & $>15$ \\
\hline
\end{tabular}


Table 2 Patient characteristics

\begin{tabular}{ll}
\hline Patient characteristics & All \\
& $n=542$ \\
\hline Age (mean \pm SD) & $63 \pm 11$ \\
Male sex (\%) & 58 \\
Hypertension (\%) & 86 \\
Diabetes (\%) & 31 \\
Coronary artery disease (\%) & 30 \\
Smoking (py) & $14 \pm 19$ \\
Body mass index (kg/m $\left.{ }^{2}\right)$ & $29 \pm 5$ \\
Septal thickness (mm) & $12 \pm 2$ \\
Posterior wall thickness (mm) & $11 \pm 2$ \\
Left ventricular mass (g). & $234[194-276]$ \\
Median [25-75 percentile] & \\
LVEDD (mm) & $51 \pm 5$ \\
LA (mm) & $41 \pm 6$ \\
EF (\%) & $60 \pm 8$ \\
Diastolic dysfunction (\%) & 71 \\
GFR (mL/min) & $82 \pm 18$ \\
\hline
\end{tabular}

parameter for the detection of diastolic dysfunction than each peptide alone. The NT-proBNP/NT-proANP ratio was highest in patients with severe diastolic dysfunction and systolic dysfunction ( $p<0.0001$ vs. normal function). However, there was no apparent difference in the increase of the ratio as compared with NT-proBNP alone.
Analysis of ROC curves

For detecting preclinical systolic dysfunction (Fig. 2, upper left panel), test characteristics were good for all three natriuretic peptides (AUC 0.751-0.831). NT-proBNP was the best diagnostic marker with borderline significant differences to NTproANP ( $p=0.054)$ and BNP $(p=0.048)$. Test characteristics of natriuretic peptides performed rather poor in detecting any diastolic dysfunction.

Figure 2, upper right panel shows the test characteristics for the detection of severe diastolic dysfunction by natriuretic peptides. Diagnostic accuracies of NT-proANP, NTproBNP and BNP and the ratio of NT-proBNP/NT-proANP were all in a high range (AUC $=0.729-0.762$, respectively; $p=0.900-0.940$ ).

Figure 2 (lower right panel) and Table 3 demonstrate that all natriuretic peptides showed good test characteristics for the detection of any ventricular dysfunction $(\mathrm{EF}<50 \%$ or severe diastolic dysfunction). Direct comparison of the natriuretic peptides revealed that the overall diagnostic performance of NT-proBNP seemed to perform best in detecting any preclinical ventricular dysfunction (AUC 0.813 ), but this difference failed to reach significance ( $p=0.167$ to NT-proANP, $p=0.086$ to BNP).

Table 4 demonstrates that in contrast to NT-proBNP obesity, renal insufficiency and age have only modest influence on the score with respect to the AUCs for systolic or severe diastolic dysfunction.

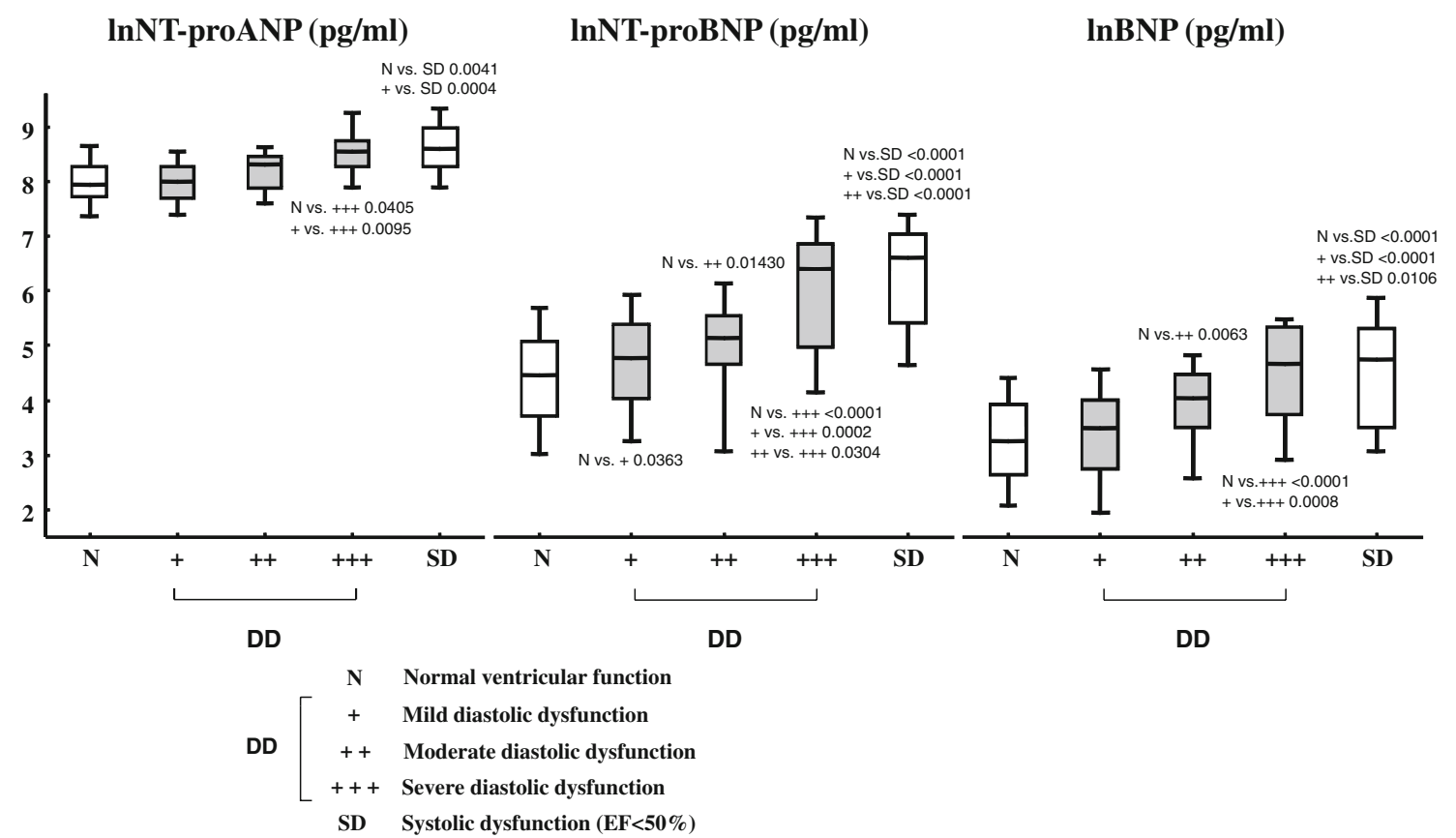

Fig. 1 Natriuretic peptides and diastolic function. Concentrations (ordinate) of lnNT-proANP (left), lnNT-proBNP (middle) and lnBNP (right) stratified by left ventricular diastolic function (normal $(\mathrm{N})$ vs. mild $(\mathrm{DD}+)$, moderate $(\mathrm{DD}++)$ or severe $(\mathrm{DD}+++)$ diastolic dysfunction; abscissa). Values for systolic dysfunction (SD; $\mathrm{EF}<50 \%$ ) are given for comparison. Boxes define the interquartile range with the median indicated by the crossbar. Error bars indicate the 10th and 90th percentiles 
Fig. 2 ROC analysis of natriuretic peptides and the score in the diagnosis of any systolic (EF > 50\%; upper left), severe diastolic (upper right) and systolic or severe diastolic (lower right) dysfunction. AUC values and statistical analysis is summarised in Table 2
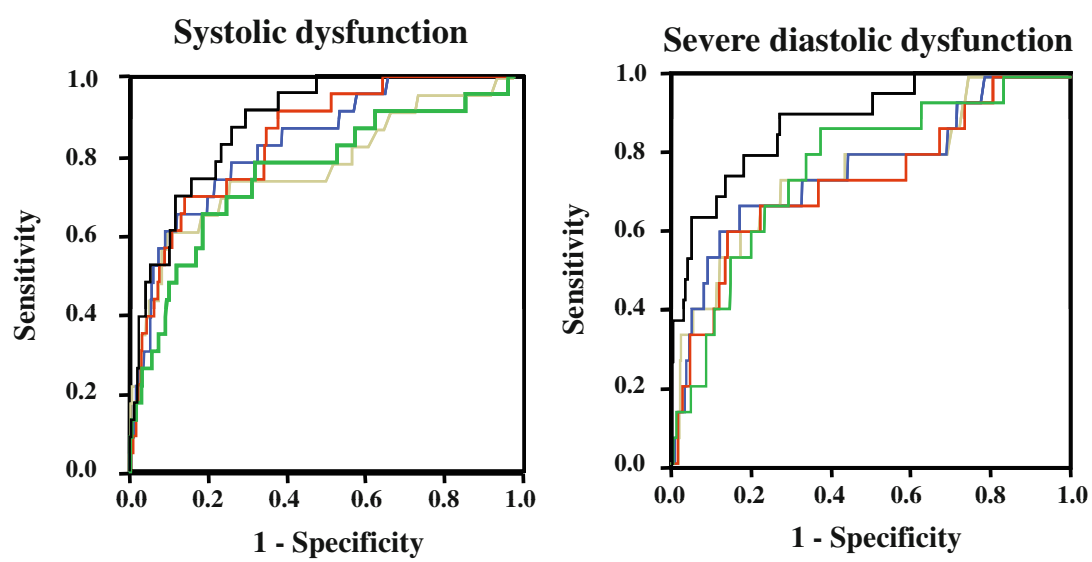

Systolic or severe diastolic dysfunction
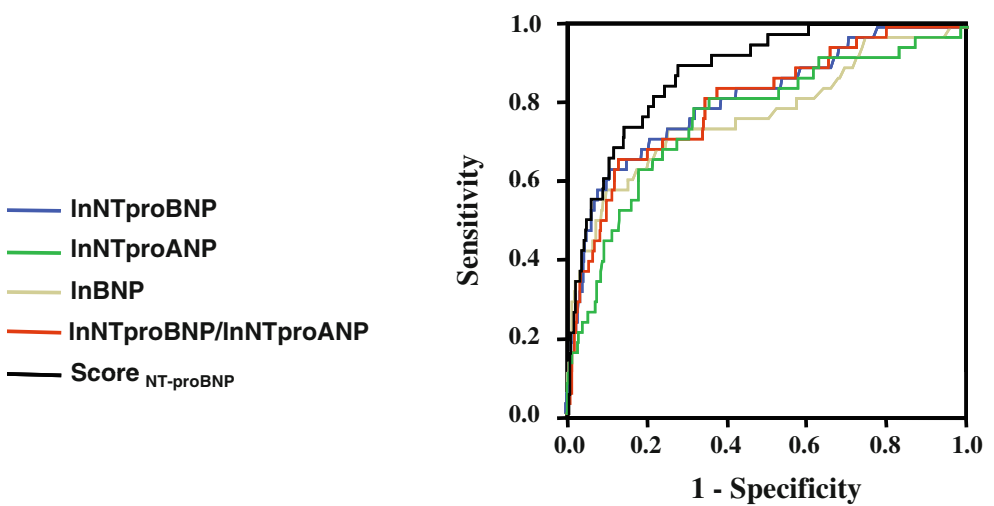

Multivariate regression analysis and testing of a multivariable scoring system

To optimise the detection of patients with preclinical ventricular dysfunction, we performed univariate and multivariate regression analysis using the following variables: lnNT-proBNP, age, hypertension, diabetes, CAD, and dyspnea on exertion. Variables were taken into the model if $p<0.05$ and were not taken out if $p<0.10$. LnNT-proBNP and dyspnea on exertion were independently associated with systolic dysfunction and lnNTproBNP, diabetes, dyspnea on exertion, hypertension and CAD were independent predictors of severe preclinical diastolic dysfunction.

For systolic or severe diastolic dysfunction lnNT-proBNP, hypertension, diabetes, CAD and dyspnea on exertion were independent predictors. From these parameters, we derived a score system that incorporated, besides InNT-proBNP, those clinical variables with the best prediction characteristics for asymptomatic left ventricular dysfunction. The score was calculated (with regression coefficients of covariates) as follows: Score $_{\text {ventricular dysfunction NT-proBNP }}=1.054 \times$ diabetes $(0=$ no, $1=$ yes $)+1.884 \times$ hypertension $+1.199 \times$ dyspnea on exertion $+0.970 \times$ coronary artery disease $+1.003 \times \operatorname{lnNT}$-proBNP.

For comparison, we also calculated a score with the aforementioned clinical variables, but without

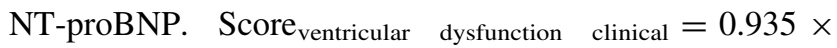
diabetes +2.256 hypertension $+1.320 \times$ dyspnea on exertion $+1.489 \times$ coronary artery disease.

We next tested the diagnostic accuracy of the score as compared with lnNT-proBNP alone and the score with NT-proBNP as compared with the score without NT-proBNP in ROC analyses (Fig. 2; Table 3). The score that combines clinical parameters with $\operatorname{lnNT}$-proBNP was of significantly better diagnostic accuracy than lnNT-proBNP alone in detecting systolic or severe diastolic dysfunction $(p=0.02)$. Moreover, the score incorporating NT-proBNP showed a significantly better diagnostic performance compared with the sole clinical score (without NT-proBNP) for the diagnosis of a systolic or severe diastolic dysfunction $(p=0.032)$.

Validation of this new score by "leave one out"-cross validation revealed a percentage of correctly specified individuals of $95 \%$ for systolic dysfunction, $93 \%$ for systolic or severe diastolic dysfunction and $96 \%$ for severe diastolic dysfunction, but only of $35 \%$ for any diastolic dysfunction. 
Table 3 AUCs for systolic and/or severe diastolic dysfunction

\begin{tabular}{|c|c|c|c|c|c|c|c|}
\hline Variable & $\mathrm{AUC}[\mathrm{CI}]$ & Cut-off & Sensitivity & Specificity & $\begin{array}{l}\text { Negative } \\
\text { predictive } \\
\text { value }\end{array}$ & $\begin{array}{l}\text { Positive } \\
\text { predictive } \\
\text { value }\end{array}$ & $\begin{array}{l}p \text { vs. Score } \\
\text { (with NT- } \\
\text { proBNP) }\end{array}$ \\
\hline \multicolumn{8}{|l|}{ Systolic dysfunction } \\
\hline LnNTproANP (pg/mL) & $0.751[0.636-0.866]$ & $8.45(4,675.07)$ & 65 & 81 & 98 & 13 & \\
\hline LnNTproBNP (pg/mL) & $0.831[0.748-0.914]$ & $5.94(379.93)$ & 65 & 88 & 98 & 19 & \\
\hline $\operatorname{LnBNP}(p g / m L)$ & $0.769[0.651-0.886]$ & $4.65(104.59)$ & 61 & 90 & 98 & 22 & \\
\hline QlnNBNP/lnNANP & $0.835[0.759-0.910]$ & 0.70 & 70 & 86 & 98 & 18 & \\
\hline Age & $0.692[0.594-0.791]$ & 67 & 65 & 66 & 98 & 8 & \\
\hline Score (with NT-proBNP) & $0.883[0.828-0.938]$ & 8.13 & 91 & 71 & 99 & 12 & \\
\hline Score (without NT-proBNP) & $0.792[0.695-0.888]$ & 3.66 & 70 & 72 & 98 & 10 & \\
\hline \multicolumn{8}{|l|}{ Severe diastolic dysfunction } \\
\hline LnNTproANP (pg/mL) & $0.762[0.647-0.878]$ & $8.19(3,604.72)$ & 87 & 63 & 99 & 6 & \\
\hline LnNTproBNP (pg/mL) & $0.758[0.620-0.895]$ & $5.67(290.03)$ & 67 & 83 & 99 & 10 & \\
\hline LnBNP (pg/mL) & $0.754[0.620-0.889]$ & $4.06(57.97)$ & 73 & 72 & 99 & 5 & \\
\hline QlnNBNP/lnNANP & $0.729[0.588-0.870]$ & 0.71 & 60 & 86 & 98 & 11 & \\
\hline Age & $0.724[0.596-0.852]$ & 69 & 67 & 73 & 99 & 6 & \\
\hline Score (with NT-proBNP) & $0.881[0.803-0.960]$ & 8.13 & 90 & 73 & 99 & 11 & \\
\hline Score (without NT-proBNP) & $0.806[0.716-0.896]$ & 3.66 & 68 & 73 & 98 & 8 & \\
\hline \multicolumn{8}{|c|}{ Systolic or severe distolic dysfunction } \\
\hline LnNTproANP (pg/mL) & $0.765[0.681-0.849]$ & $8.25(3,827.63)$ & 79 & 68 & 98 & 16 & 0.004 \\
\hline LnNTproBNP (pg/mL) & $0.813[0.738-0.888]$ & $5.94(379.93)$ & 63 & 89 & 97 & 30 & 0.022 \\
\hline LnBNP (pg/mL) & $0.772[0.683-0.862]$ & $4.06(57.97)$ & 74 & 75 & 97 & 18 & 0.001 \\
\hline QlnNBNP/lnNANP & $0.803[0.729-0.877]$ & 0.70 & 66 & 87 & 97 & 27 & 0.011 \\
\hline Age & $0.712[0.633-0.792]$ & 69 & 61 & 74 & 96 & 15 & 0.001 \\
\hline Score (with NT-proBNP) & $0.882[0.831-0.932]$ & 8.13 & 90 & 72 & 99 & 20 & \\
\hline Score (without NT-proBNP) & $0.805[0.732-0.877]$ & 3.66 & 68 & 73 & 97 & 16 & 0.032 \\
\hline
\end{tabular}

Table 4 Comorbidities and AUCs for systolic or severe diastolic dysfunction

\begin{tabular}{lll}
\hline Comorbidity & Variable & AUC \\
\hline Obesity & & \\
BMI $<25 \mathrm{~kg} / \mathrm{m}^{2}$ & Score (with NT-proBNP) & 0.904 [0.816-0.992] \\
& Score (without NT-proBNP) & 0.818 [0.631-1.000] \\
BMI $>25 \mathrm{~kg} / \mathrm{m}^{2}$ & Score (with NT-proBNP) & 0.879 [0.821-0.937] \\
& Score (without NT-proBNP) & 0.801 [0.722-0.881] \\
Renal insufficiency & & 0.867 [0.808-0.925] \\
Estimated glomerular filtration rate $>60 \mathrm{~mL} / \mathrm{min}$ & Score (with NT-proBNP) & 0.788 [0.699-0.878] \\
& Score (without NT-proBNP) & 0.945 [0.888-1.000] \\
Estimated glomerular filtration rate $<60 \mathrm{~mL} / \mathrm{min}$ & Score (with NT-proBNP) & 0.826 [0.721-0.931] \\
Age & Score (without NT-proBNP) & \\
$<70$ years & & 0.898 [0.829-0.966] \\
$>70$ years & Score (with NT-proBNP) & 0.814 [0.709-0.918] \\
& Score (without NT-proBNP) & 0.819 [0.719-0.919] \\
\hline
\end{tabular}


Optimised screening approach for asymptomatic left ventricular dysfunction

We compared different possible screening strategies to detect severe ventricular dysfunction (i.e., EF $<50 \%$ or/ and severe diastolic dysfunction; Table 5). By definition, a strategy that applies screening echocardiography to all patients at risk has $100 \%$ sensitivity and specificity and a positive likelihood ratio of 1 , but the number needed to screen for one patient positive for the diagnosis is 14.3. Including NT-proBNP (cut-off $209.5 \mathrm{pg} / \mathrm{mL}$ ) into the diagnostic workup reduces sensitivity and specificity to 74 and $75 \%$, respectively, but also largely reduces the number of screening echoes needed to identify one patient with any preclinical ventricular dysfunction to 5.5 (at the expense, however, of $26 \%$ positives missed). The most efficient strategy (see number needed to screen) is to apply echocardiography to all patients with diabetes and a NT-proBNP above the cut-off level of $209.5 \mathrm{pg} / \mathrm{mL}$. Every third patient screened will be diagnosed to have severe ventricular dysfunction; however, with this approach only one-third of all patients with severe ventricular dysfunction would be detected.

Overall test characteristics were best for the developed screening score: using this score (cut-off set at 8.551 points), sensitivity and specificity for accurate diagnosis were 82 and $79 \%$, respectively; the number of screening echoes needed to identify one affected patient was 4.5 , with only $18 \%$ of positive patients missed (Table 5). Figure 3 shows the superiority of the score system that combines clinical and $\operatorname{lnNT}$-proBNP values versus $\operatorname{lnNT}$-proBNP alone in identifying patients in need of echocardiography. With increasing sensitivity, the score largely reduced the number of echoes needed as compared with NT-proBNP alone. For instance, to detect at least $80 \%$ of the affected patients, this would necessitate echocardiography in $42 \%$ of participants if decision was based on NT-proBNP only as compared with $26 \%$ (relative reduction of $38 \%$ ) when using the score.

\section{Discussion}

The present study demonstrates that in patients at risk for $\mathrm{HF}$, natriuretic peptides help diagnosing systolic and severe diastolic dysfunction. A score system that combines clinical parameters with natriuretic peptide measurement provides additive diagnostic accuracy for asymptomatic systolic or severe diastolic dysfunction.

Our study has two new findings:

1. A combination of clinical variables with natriuretic peptides (either BNP or NT-proBNP) in a scoring system is superior to natriuretic peptides alone and is superior to a scoring system without NT-proBNP in diagnosing systolic and severe diastolic dysfunctions. Moreover, the implementation of such a score may reduce the need for echocardiography in a primarycare based screening programme for left ventricular dysfunction.

2. The combination of natriuretic peptides by forming a ratio between two (e.g. NT-proBNP and NT-proANP) is not superior to the value of each natriuretic peptide alone.

Role of natriuretic peptides in the detection of ventricular dysfunction

The role of natriuretic peptides in the detection of left ventricular systolic dysfunction is well established [13]. In line with this and other previous observations, in our study NT-proANP, BNP and NT-proBNP were significantly higher in patients with preclinical systolic dysfunction compared with patients with normal systolic function [31].

Table 5 Different screening models

\begin{tabular}{|c|c|c|c|c|c|c|c|c|c|}
\hline & Models & $\begin{array}{l}\text { Sensitivity } \\
(\%)\end{array}$ & $\begin{array}{l}\text { Specificity } \\
(\%)\end{array}$ & $\mathrm{LR}+$ & LR- & $\begin{array}{l}\text { Needing NT- } \\
\text { proBNP }(\%)\end{array}$ & $\begin{array}{l}\text { Needing } \\
\text { Echo }(\%)\end{array}$ & $\begin{array}{l}\text { Disease } \\
\text { missed }(\%)\end{array}$ & $\begin{array}{l}\text { NNS by } \\
\text { Echo }\end{array}$ \\
\hline 1 & Echo in all & 100 & 100 & 1.0 & 0 & 0 & 100 & 0 & 14.3 \\
\hline 2 & NT-proBNP only, cut-off $209.5 \mathrm{pg} / \mathrm{mL}$ & 74 & 75 & 2.9 & 0.4 & 100 & 29 & 26 & 5.5 \\
\hline 3 & Echo in all with dyspnea & 71 & 67 & 2.2 & 0.4 & 0 & 35 & 29 & 7.1 \\
\hline 4 & $\begin{array}{l}\text { If dyspnea, than NT-proBNP (cut-off } \\
209.5 \mathrm{pg} / \mathrm{mL} \text { ) }\end{array}$ & 53 & 89 & 4.8 & 0.5 & 35 & 14 & 47 & 3.8 \\
\hline 5 & Echo in all with diabetes, dyspnea or CAD & 95 & 36 & 1.5 & 0.1 & 0 & 67 & 5 & 10.0 \\
\hline 6 & $\begin{array}{l}\text { If diabetes, dyspnea or CAD, than } \\
\text { NT-proBNP (cut-off } 209.5 \mathrm{pg} / \mathrm{mL} \text { ) }\end{array}$ & 68 & 83 & 3.9 & 0.4 & 67 & 21 & 32 & 4.4 \\
\hline 7 & Score $_{\text {clinical }}$ (cut-off 3.66 units) & 68 & 73 & 2.5 & 0.4 & 0 & 30 & 32 & 6.2 \\
\hline 8 & Score $_{\text {NT-proBNP }}$ (cut-off 8.551 units) & 82 & 79 & 3.8 & 0.2 & 100 & 26 & 18 & 4.5 \\
\hline
\end{tabular}




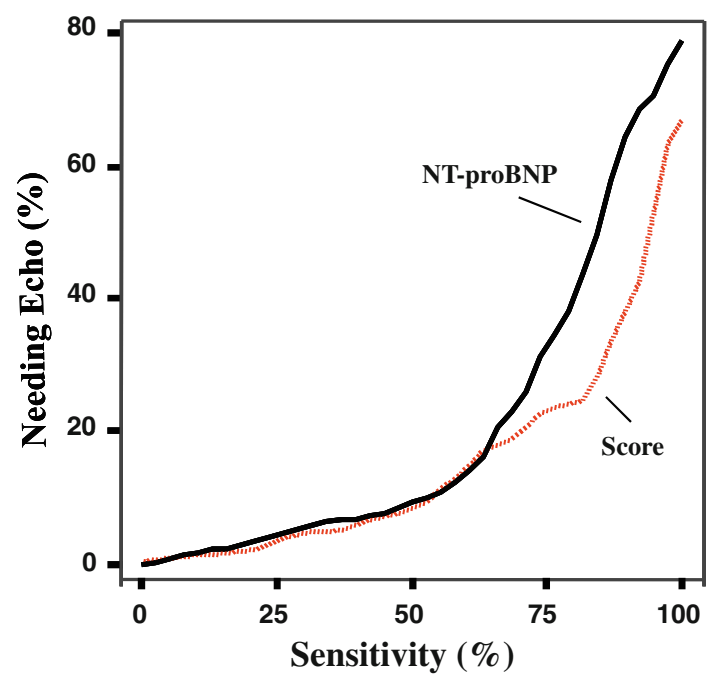

Fig. 3 Score system in comparison to NT-proBNP alone in identifying patients at risk for any systolic or severe diastolic left ventricular dysfunction needing an echocardiogram. The number of patients needing an echocardiogram (abscissa) is plotted versus sensitivity of the test procedure

The diagnostic value of natriuretic peptides in detecting diastolic dysfunction is by far more controversial, and published reports showed heterogeneous results. An initial report by Lubien et al. [22] showed very good test characteristics of BNP for the detection of diastolic dysfunction. Later reports could not confirm these optimistic results. Grewal et al. could demonstrate that natriuretic peptides were the strongest independent predictors of diastolic dysfunction, as determined by Doppler-echocardiography in the CHARM-Preserved trial. Of importance, these patients suffered from HF, whereas the patients in our study were symptom-free $[11,12,28]$. In this study, we could demonstrate that natriuretic peptides do not accurately predict mild or moderate diastolic dysfunction, but are a very valuable tool to identify patients with severe diastolic dysfunction. This finding is in line with those of Costello-Boerrigter et al. and Redfield et al., who found that NT-proBNP or BNP may be useful to detect moderate/ severe diastolic dysfunction [6,30].

One explanation for the differences between our study and previously published studies may be that Lubien et al. analysed a group of highly selected patients referred to an echocardiographic laboratory, whereas others chose a population-based sample [22, 28]. Due to this referral bias, pretest probability in these studies is quite different with significant effects on further final test results. Another explanation is the definition of diastolic dysfunction. Redfield et al. [30] required two independent echocardiographic signs of at least moderate diastolic dysfunction to establish the diagnosis. In line with this approach we defined severe diastolic dysfunction as a restrictive filling pattern and/or indications of elevated filling pressure (left atrial diameter $>45 \mathrm{~mm}$ and $\mathrm{E} / \mathrm{Ea}>15)$ [25]. An increased left atrial diameter or volume as well as an E/Ea $>15$ has been associated with elevated filling pressure in patients with HF and a normal $\mathrm{EF}[24,26]$. Our results demonstrate that natriuretic peptides may have a pivotal role in the screening for severe diastolic or any systolic dysfunction in a primary care setting.

\section{Comparison of NT-proANP, NT-proBNP and BNP}

in the detection of preclinical left ventricular dysfunction

Our study design allowed the direct comparison of NT-proANP, NT-proBNP and BNP in the detection of systolic or diastolic dysfunction by either comparative ROC analysis or comparative correlation analysis. NTproBNP tended to be the best marker of systolic and severe diastolic dysfunction. However, the difference between NT-proBNP and BNP in diagnosing diastolic and systolic dysfunctions was not statistically significant, confirming results from two other studies for the diagnosis of systolic dysfunction $[6,16]$.

We further hypothesised that the combination of two markers could improve diagnostic accuracy. Since atrial emptying into the ventricle is impaired, atrial wall stress should be elevated in diastolic dysfunction. However, with increasing degree of diastolic dysfunction, the NT-proBNP to NT-proANP ratio increased, indicating that NT-proBNP up-regulation outranges NT-proANP up-regulation in more severe diastolic dysfunction. The NT-proBNP to NT-proANP ratio did not give additional diagnostic value as compared with NT-proBNP alone.

These surprising results challenge the simple concept of ANP mainly secreted by the atria and BNP mainly secreted by the ventricles. Data from an invasive study with selective coronary sinus blood sampling showed that in atrial fibrillation, BNP is mainly secreted from the left atrium, and not from the ventricle [17]. Thus, as all natriuretic peptides are rather simultaneously regulated in systolic and diastolic dysfunction, it seems more attractive to identify the most sensitive biochemical marker.

\section{Clinical implications}

The recent definition of HF by the American Heart Association denotes stages A-D and requires identification of patients with structural heart disease (stage B) [3]. To evaluate the impact of natriuretic peptides as a screening tool for patients at risk for developing HF, three assumptions are made: (1) the prevalence of the disease is high enough in the population studied. With an 
overall prevalence of $7 \%$ for severe diastolic dysfunction and systolic dysfunction in the population studied, this condition is fulfilled; (2) a therapy for these patients in an asymptomatic stage of the disease is provided. This holds true for systolic dysfunction as, e.g. ACE inhibitors reduce progression to overt $\mathrm{HF}$, but the situation is less clear for severe diastolic dysfunction [1, 2]; (3) there is a diagnostic test with a high sensitivity and specificity. A screening test should have a high negative predictive power, so that a test result below the cut-off point is much more likely in patients without the disease. From our results, our score system incorporating NTproBNP provides good diagnostic accuracy, especially for systolic or severe diastolic dysfunction. Therefore, an important finding of our study is that the combination of specific clinical information with a point measure of NTproBNP improves diagnostic accuracy over each strategy alone.

\section{Limitations of the study}

Our risk estimation model may not be ready for clinical use because we developed and validated it in the same study population. Validation of our model in an independent cohort may be necessary before clinical application can be recommended.

Parameters of electrocardiography have been previously used to screen for diastolic dysfunction (Galasko et al. and Goode et al.). In our study, we aimed to screen for diastolic dysfunction without electrocardiograms. The information given by ECG may be of incremental value to clinical information. Therefore, in further studies screening for diastolic dysfunction, ECG should be included [7, 9].

\section{Conclusion}

In conclusion, the prevalence of preclinical diastolic dysfunction in a risk cohort is high, but the relative proportion of severe diastolic dysfunction is rather low. Natriuretic peptides are useful to detect systolic and severe diastolic dysfunction. The additional use of clinical information optimises a biomarker-based screening approach. Thus, natriuretic peptides should be considered as additional clinical information and their use in combination with other clinical data should be considered for Public Health screening algorithms to reduce the HF burden.

Acknowledgments This study was supported by grants from the German Federal Ministry of Education and Research (MedVIP Study and Competence Network of Heart Failure, TP7, FKZ 01GI0205). Roche Diagnostics (Mannheim, Germany) kindly provided the NT-proBNP test kits.
Open Access This article is distributed under the terms of the Creative Commons Attribution Noncommercial License which permits any noncommercial use, distribution, and reproduction in any medium, provided the original author(s) and source are credited.

\section{References}

1. (1992) Effect of enalapril on mortality and the development of heart failure in asymptomatic patients with reduced left ventricular ejection fractions. The SOLVD investigators. N Engl J Med 327:685-691

2. (1991) Effect of enalapril on survival in patients with reduced left ventricular ejection fractions and congestive heart failure. The SOLVD investigators. N Engl J Med 325:293-302

3. Bonow RO, Bennett S, Casey DE Jr, Ganiats TG, Hlatky MA, Konstam MA, Lambrew CT, Normand SL, Pina IL, Radford MJ, Smith AL, Stevenson LW, Burke G, Eagle KA, Krumholz HM, Linderbaum J, Masoudi FA, Ritchie JL, Rumsfeld JS, Spertus JA (2005) ACC/AHA clinical performance measures for adults with chronic heart failure: a report of the American College of Cardiology/American Heart Association Task Force on Performance Measures (Writing Committee to Develop Heart Failure Clinical Performance Measures): endorsed by the Heart Failure Society of America. Circulation 112:1853-1887

4. Cheitlin MD, Armstrong WF, Aurigemma GP, Beller GA, Bierman FZ, Davis JL, Douglas PS, Faxon DP, Gillam LD, Kimball TR, Kussmaul WG, Pearlman AS, Philbrick JT, Rakowski H, Thys DM, Antman EM, Smith SC Jr, Alpert JS, Gregoratos G, Anderson JL, Hiratzka LF, Hunt SA, Fuster V, Jacobs AK, Gibbons RJ, Russell RO (2003) ACC/AHA/ASE 2003 guideline update for the clinical application of echocardiography: summary article. A report of the American College of Cardiology/American Heart Association Task Force on Practice Guidelines (ACC/ AHA/ASE Committee to Update the1997 Guidelines for the Clinical Application of Echocardiography). J Am Soc Echocardiogr 16:1091-1110

5. Chen AA, Wood MJ, Krauser DG, Baggish AL, Tung R, Anwaruddin S, Picard MH, Januzzi JL (2006) NT-proBNP levels, echocardiographic findings, and outcomes in breathless patients: results from the ProBNP Investigation of Dyspnoea in the Emergency Department (PRIDE) echocardiographic substudy. Eur Heart J 27:839-845

6. Costello-Boerrigter LC, Boerrigter G, Redfield MM, Rodeheffer RJ, Urban LH, Mahoney DW, Jacobsen SJ, Heublein DM, Burnett JC Jr (2006) Amino-terminal pro-B-type natriuretic peptide and B-type natriuretic peptide in the general community: determinants and detection of left ventricular dysfunction. J Am Coll Cardiol 47:345-353

7. Galasko GI, Barnes SC, Collinson P, Lahiri A, Senior R (2006) What is the most cost-effective strategy to screen for left ventricular systolic dysfunction: natriuretic peptides, the electrocardiogram, hand-held echocardiography, traditional echocardiography, or their combination? Eur Heart J 27:193-200

8. Goetze JP, Friis-Hansen L, Rehfeld JF, Nilsson B, Svendsen JH (2006) Atrial secretion of B-type natriuretic peptide. Eur Heart J 27:1648-1650

9. Goode KM, Clark AL, Bristow JA, Sykes KB, Cleland JG (2007) Screening for left ventricular systolic dysfunction in high-risk patients in primary-care: a cost-benefit analysis. Eur J Heart Fail 9:1186-1195

10. Gorelik O, Almoznino-Sarafian D, Shteinshnaider M, Alon I, Tzur I, Sokolsky I, Efrati S, Babakin Z, Modai D, Cohen N (2009) Clinical variables affecting survival in patients with 
decompensated diastolic versus systolic heart failure. Clin Res Cardiol 98:224-232

11. Grewal J, McKelvie R, Lonn E, Tait P, Carlsson J, Gianni M, Jarnert C, Persson H (2008) BNP and NT-proBNP predict echocardiographic severity of diastolic dysfunction. Eur J Heart Fail 10:252-259

12. Grewal J, McKelvie RS, Persson H, Tait P, Carlsson J, Swedberg K, Ostergren J, Lonn E (2008) Usefulness of N-terminal probrain natriuretic Peptide and brain natriuretic peptide to predict cardiovascular outcomes in patients with heart failure and preserved left ventricular ejection fraction. Am J Cardiol 102:733737

13. Groenning BA, Raymond I, Hildebrandt PR, Nilsson JC, Baumann M, Pedersen F (2004) Diagnostic and prognostic evaluation of left ventricular systolic heart failure by plasma N-terminal probrain natriuretic peptide concentrations in a large sample of the general population. Heart 90:297-303

14. Hawkins DM, Basak SC, Mills D (2003) Assessing model fit by cross-validation. J Chem Inf Comput Sci 43:579-586

15. Hettwer S, Panzner-Grote B, Witthaut R, Werdan K (2007) Isolated diastolic dysfunction-diagnostic value of tissue Doppler imaging, colour M-mode and $\mathrm{N}$-terminal pro B-type natriuretic peptide. Clin Res Cardiol 96:874-882

16. Hobbs FD, Davis RC, Roalfe AK, Hare R, Davies MK (2004) Reliability of N-terminal proBNP assay in diagnosis of left ventricular systolic dysfunction within representative and high risk populations. Heart 90:866-870

17. Inoue S, Murakami Y, Sano K, Katoh H, Shimada T (2000) Atrium as a source of brain natriuretic polypeptide in patients with atrial fibrillation. J Card Fail 6:92-96

18. Johnston B, Seshia SS (1992) Discriminant analysis when all variables are ordered. Stat Med 11:1023-1032

19. Koschack J, Scherer M, Luers C, Kochen MM, Wetzel D, Kleta S, Pouwels C, Wachter R, Herrmann-Lingen C, Pieske B, Binder L (2008) Natriuretic peptide vs. clinical information for diagnosis of left ventricular systolic dysfunction in primary care. BMC Fam Pract 9:14

20. Lee WC, Chavez YE, Baker T, Luce BR (2004) Economic burden of heart failure: a summary of recent literature. Heart Lung 33:362-371

21. Letsas KP, Filippatos GS, Pappas LK, Mihas CC, Markou V, Alexanian IP, Efremidis M, Sideris A, Maisel AS, Kardaras F (2009) Determinants of plasma NT-pro-BNP levels in patients with atrial fibrillation and preserved left ventricular ejection fraction. Clin Res Cardiol 98:101-106

22. Lubien E, DeMaria A, Krishnaswamy P, Clopton P, Koon J, Kazanegra R, Gardetto N, Wanner E, Maisel AS (2002) Utility of B-natriuretic peptide in detecting diastolic dysfunction: comparison with Doppler velocity recordings. Circulation 105:595-601

23. Mottram PM, Leano R, Marwick TH (2003) Usefulness of B-type natriuretic peptide in hypertensive patients with exertional dyspnea and normal left ventricular ejection fraction and correlation with new echocardiographic indexes of systolic and diastolic function. Am J Cardiol 92:1434-1438
24. Nagueh SF, Rao L, Soto J, Middleton KJ, Khoury DS (2004) Haemodynamic insights into the effects of ischaemia and cycle length on tissue Doppler-derived mitral annulus diastolic velocities. Clin Sci (Lond) 106:147-154

25. Paulus WJ, Tschope C, Sanderson JE, Rusconi C, Flachskampf FA, Rademakers FE, Marino P, Smiseth OA, De Keulenaer G, Leite-Moreira AF, Borbely A, Edes I, Handoko ML, Heymans S, Pezzali N, Pieske B, Dickstein K, Fraser AG, Brutsaert DL (2007) How to diagnose diastolic heart failure: a consensus statement on the diagnosis of heart failure with normal left ventricular ejection fraction by the Heart Failure and Echocardiography Associations of the European Society of Cardiology. Eur Heart J 28:2539-2550

26. Poerner TC, Goebel B, Unglaub P, Sueselbeck T, Strotmann JM, Pfleger S, Borggrefe M, Haase KK (2003) Detection of a pseudonormal mitral inflow pattern: an echocardiographic and tissue Doppler study. Echocardiography 20:345-356

27. Quinones MA, Otto CM, Stoddard M, Waggoner A, Zoghbi WA (2002) Recommendations for quantification of Doppler echocardiography: a report from the Doppler Quantification Task Force of the Nomenclature and Standards Committee of the American Society of Echocardiography. J Am Soc Echocardiogr $15: 167-184$

28. Redfield MM (2004) Understanding "diastolic" heart failure. N Engl J Med 350:1930-1931

29. Redfield MM, Jacobsen SJ, Burnett JC Jr, Mahoney DW, Bailey KR, Rodeheffer RJ (2003) Burden of systolic and diastolic ventricular dysfunction in the community: appreciating the scope of the heart failure epidemic. JAMA 289:194-202

30. Redfield MM, Rodeheffer RJ, Jacobsen SJ, Mahoney DW, Bailey KR, Burnett JC Jr (2004) Plasma brain natriuretic peptide to detect preclinical ventricular systolic or diastolic dysfunction: a community-based study. Circulation 109:3176-3181

31. Richards M, Troughton R, Lainchbury J, Doughty R, Wright S (2005) Health gains by using natriuretic peptides in diagnosis, prognosis and treatment. Scand J Clin Lab Invest Suppl 240:129137

32. Rossi A, Cicoira M, Florea VG, Golia G, Florea ND, Khan AA, Murray ST, Nguyen JT, O'Callaghan P, Anand IS, Coats A, Zardini P, Vassanelli C, Henein M (2006) Chronic heart failure with preserved left ventricular ejection fraction: diagnostic and prognostic value of left atrial size. Int J Cardiol 110:386-392

33. Solomon SD, Janardhanan R, Verma A, Bourgoun M, Daley WL, Purkayastha D, Lacourciere Y, Hippler SE, Fields H, Naqvi TZ, Mulvagh SL, Arnold JM, Thomas JD, Zile MR, Aurigemma GP (2007) Effect of angiotensin receptor blockade and antihypertensive drugs on diastolic function in patients with hypertension and diastolic dysfunction: a randomised trial. Lancet 369:20792087

34. Wachter R, Luers C, Kleta S, Griebel K, Herrmann-Lingen C, Binder L, Janicke N, Wetzel D, Kochen MM, Pieske B (2007) Impact of diabetes on left ventricular diastolic function in patients with arterial hypertension. Eur J Heart Fail 9:469-476

35. Youden W (1950) Index for rating diagnostic tests. Cancer 3:32-35 